Praxis, Vol. 14, No. 2, 215 - 225

DOI: http://dx.doi.org/10.21676/23897856.2763

\title{
(Des)cortesía y modalización en el contexto de la educación básica $(\mathrm{Im})$ politeness and modalization in basic education background
}

\author{
Roberto Osuna Bermúdez ${ }^{1}$
}

Tipología: artículo de reflexión

Para citar este artículo: Osuna, R. (2018). (Des)cortesía y modalización en el contexto de educación básica. Praxis, 14(2), 215-225. Doi: http://dx.doi.org/10.21676/23897856.2763

Recibido en agosto 27 de 2018

Aceptado en diciembre 10 de 2018

Publicado en línea en diciembre 16 de 2018

\section{RESUMEN}

Este artículo constituye una aproximación teórico-descriptiva de carácter cualitativo, cuyo propósito es detallar la incidencia de la modalización y la (des)cortesía en las interacciones verbales, para resolver los conflictos interpersonales de diecisiete estudiantes de grado séptimo en una institución educativa distrital de la localidad de Ciudad Bolívar, en Bogotá, Colombia. La investigación se desarrolla con una orientación sociopragmática y de acuerdo con algunos elementos de la enunciación. Se encuentra que las infracciones a los turnos de conversación y algunos comportamientos verbales y no verbales constituyen formas de cortesía o descortesía. Este análisis se fundamenta en las acciones comunicativas, en particular, la manera en que los estudiantes realizan sugerencias y dan opiniones.

Palabras clave: cortesía; descortesía; interacción verbal; modalización; sociopragmática.

\begin{abstract}
This article is a descriptive theoretical approach based on qualitative nature, whose purpose is to detail the incidence of modalization and (im)politeness in verbal interactions to resolve interpersonal conflicts of 17 seventh graders of a district educational institution of Ciudad Bolívar, in Bogotá, Colombia. This research is developed with a sociopragmatic orientation and it is also based on some enunciation elements. Therefore, conversation shifts, some verbal and nonverbal behaviors take part of politeness or impoliteness; this analysis is based on communicative actions, in particular, the way students make suggestions and express opinions.
\end{abstract}

Keywords: Politeness; Impoliteness; Verbal Interaction; Modalization; Sociopragmatic.

\footnotetext{
${ }^{1}$ Mag. en Pedagogía de la Lengua Materna. Universidad Distrital Francisco José de Caldas, Bogotá, Colombia. Correo electrónico: robertosuna999@gmail.com,rosuna@educacionbogota.edu.co ORCID 0000-0002-2449-5285
} 


\section{INTRODUCCIÓN}

$E$ ste artículo realiza un análisis en el marco de la pragmática social y es desarrollado a partir de los planteamientos de Bravo (2005), Briz (2005) y Haverkate (1987, 1996). A partir de los cuales el objetivo principal es abordar, según algunos elementos de la enunciación, cómo ciertos fenómenos de (des)cortesía se dan entre estudiantes de grado séptimo de una institución educativa distrital ubicada en la localidad de Ciudad Bolívar, Bogotá, Colombia. Dentro de estos fenómenos se encuentran: el uso del hipocorístico a manera de burla, el uso de la proxemia como ejercicio de exclusión y la modalización. El contexto socioescolar se caracteriza por acoger a personas de diversas condiciones y orígenes, es el lugar en el que las manifestaciones corteses son utilizadas escasamente por algunos de sus miembros; en consecuencia, se generan situaciones de conflicto interpersonales y de comunicación.

Igualmente, el uso indiscriminado de los turnos de la conversación genera sensibilidad cuando se presenta un carácter agraviante. Los usos lingüísticos de los escolares muestran abundancia en estos tipos de violaciones; además, el manejo del disfemismo como manifestación de descortesía afecta la proyección personal (imagen) de los estudiantes en la interacción verbal y social. Estas formas lingüísticas que los escolares ponen en práctica a través de la lengua desencadenan comportamientos agresivos, tanto físicos como verbales.

La investigación que dio lugar a esta reflexión, se desarrolló a partir de una mirada al contexto etnográfico escolar en el que se encontraron faltas en la comunicación. La burla del físico, las expresiones de disfemismo, la exclusión en el trabajo grupal e ignorar lo que menciona algún estudiante en el aula de clase, son fallas comunicativas que afectan la forma en que se presenta una persona en el acto comunicativo.

La experiencia investigativa fue de corte cualitativo, se enfocó en el análisis hermenéutico y en la descripción de la realidad escolar particular con el objetivo de observar aspectos de la oralidad (la interacción verbal y la cortesía) en la resolución de conflictos en el contexto escolar. El análisis se centró en la relación sujeto-objeto en la cual las personas que formaron este micro-escenario escolar tomaron parte en su transformación (Gurdián 2007).

La muestra estuvo integrada por 17 estudiantes de uno de los grados de bachillerato y el docente investigador de una instititución educativa de Bogotá. Como técnica de recolección se realizaron alrededor de 20 horas de grabación en audio y vídeo los cuales se transcribieron en detalle, con la autorizacion previa necesaria. Además, se realizaron entrevistas a estudiantes de manera orientadora y coordinada, lo que permitió la recolección, observación y análisis del corpus frente a las prácticas que se correlacionan con formas de cortesía, descortesía y modalización en el contexto escolar, así como, su incidencia en la resolución del conflicto escolar. A partir de este trazado, el docente investigador decidió cuáles elementos detallados se ajustan en el desarrollo del proceso de investigación que se sustenta en la etnografía a partir de la descripción minuciosa y el contraste con la teoría. Asimismo, el diario de campo fue fundamental para determinar los elementos relevantes en la investigación, pues esto permitió estudiar el lenguaje in situ debido a que por medio del análisis conversacional se examina la forma en la que se relacionan los patrones de conducta sociales y los usos lingüísticos. En los diarios de campo de cada sesión se realizó una transcripción que adaptó el modelo planteado por Calsamiglia y Tusón (1999). En consecuencia se establecieron ciertos diacríticos para 
la reproducción de las conversaciones. Algunos de ellos son:

Participantes: D: docente; E: estudiante; P: pareja; H: hablante; O: oyente; I: interactor

Elementos de interés: $\rightarrow$ : información importante; // pausa o silencio;

Elementos no verbales: ${ }^{\circledR}$ : risas de los compañeros,

Formas del lenguaje: alargamiento de un sonido vocálico,

Formas de cortesía: •: cortesía verbal,

Formas de modalización: $\longrightarrow$

Además de la transcripción de cada uno de los encuentros conversacionales, el análisis se apoyó en la observación de los videos que evidenciaban las formas de (des)cortesía en otros ámbitos y que juegan un rol importante durante el trabajo en el salón de clase.

A partir de lo expuesto, este artículo se organiza en el desarrollo de la reflexión y finalmente se exponen algunas conclusiones que se desprenden del estudio.

\section{DESARROLLO DE LA REFLEXIÓN}

\section{Origen de la cortesía}

El concepto de cortesía se construye desde los postulados del interaccionismo simbólico, el concepto de imagen y los factores sociales. Para el interaccionismo de Goffman (1991) la noción del yo o self se entiende como la proyección de la imagen personal en un evento situacional, esta representación se define exclusivamente por la situación y se recrea por su implicación en la interacción. Luego, aparece el término face o imagen acuñado por Brown y Levinson (1987). Para ellos, ésta consiste en la imagen positiva y negativa. Dos imágenes cuyos objetivos se distancian. La primera, la positiva, busca la aprobación de los demás partícipes del evento comunicativo; mientras que en la imagen negativa el interactor se desenvuelve con toda libertad de acuerdo con sus criterios. Por su parte, Haverkate (1987) define cortesía como un fenómeno modelado por factores socioculturales que, además, reglamenta ciertos acuerdos en las comunidades. En síntesis, el concepto en mención refiere un conjunto de estrategias puestas en escena durante eventos conversacionales para equilibrar los objetivos de los partícipes.

Haverkate (1996) incluso considera que uno de los tipos de cortesía es la asertiva, entendida como la intención de que el hablante manifieste su interés y veracidad en relación con lo que enuncia. En esta tipología se distinguen estrategias prototípicas como la "mitigación de la fuerza asertiva, la repetición léxica y la ironía" (p.47). De este conjunto, resultó de importancia investigativa la mitigación, que en este contexto se denomina modalización, pues permite que un hablante persuada a otro para alcanzar lo que se plantea; en consecuencia, se vale de convenciones que existen en la lengua, y de este modo, se resta fuerza a lo que se enuncia en clave de no ser evaluado como descortés y alcanzar así su propósito inicial en eventos conversacionales.

A propósito de la descortesía, en el marco de lo tradicional, ésta se asocia con actitudes soeces o de grosería. En las relaciones escolares cotidianas se despliegan una serie de acciones que tienen por objeto atacar la imagen del interlocutor. Brown y Levinson (1987) la conciben como "el uso de expresiones de desaprobación, crítica, desprecio o ridículo, regaños, acusaciones o insultos, [...] 
contradicciones o desacuerdos, [...] expresiones de violencia, irreverencia, carencia de cooperación en la actividad comunicativa al interrumpir o al no mostrar atención" (p.66). Son múltiples las acciones que se realizan y que pueden ser evaluadas como descorteses. Sin embargo, en el contexto escolar es de carácter beligerante el insulto, ya que pasa por encima de la imagen que se pretende construir. Lo anterior concuerda con la definición de descortesía como una acción formal cuyo propósito es alterar el equilibrio interpersonal (Bolívar, 2005). Este tipo de actos genera afección en las interacciones sociales y verbales que se dan en el contexto escolar.

Sin embargo, Devis (2011) considera que uno de los aspectos por considerar en el análisis de la (des)cortesía es la entonación. De manera que su estudio busca subsanar la carencia frente a este vacío teórico que se ha abordado de manera superflua. Esta disertación profundiza en cómo se crean aspectos corteses en la atenuación melódica y, de otro lado, cómo se producen fenómenos de descortesía en la intensificación melódica. Así pues, el autor asegura que la descortesía se relaciona con los rasgos suprasegmentales derivados de la entonación, pues las características melódicas son determinantes a la hora de evaluar un enunciado descortés, atenuado o cortés.

En cambio, la cortesía como manifestación de la lengua se produce en contextos particulares y, por tanto, no puede estudiarse de manera aislada. Así, pues, este análisis se realiza desde la sociopragmática —o pragmática sociocultural-, que tiene como objeto de análisis al "lenguaje inserto en su contexto social" (Bravo, 2005, p.23). Este planteamiento, además de abarcar el análisis lingüístico y extralingüístico, incluye el contexto social en el que estas manifestaciones ocurren. Este enfoque se convierte entonces en base de análisis de las interacciones verbales, lo que patenta el traspaso de los saberes que se construyen en la conciencia social y se disponen en las actuaciones diarias de los escolares.

Asimismo, la sociopragmática busca darle valor a lo extralingüístico como jerarquía de análisis, a fin de establecer una relación entre el sistema lingüístico y el social (Bravo, 2005). Una primera implicación de dicha disciplina es que los saberes de la cultura se replican en los eventos de comunicación, ya que cada individuo, por medio del lenguaje, refleja la comunidad a la que pertenece. Esto se opone a la noción de comunidad de habla (Gumperz, 1981), por cuanto cada colectivo que comparte el conocimiento lingüístico permite la interpretación, pero ello varía de persona a persona en términos de situación y modos en que suceden los eventos comunicativos. Una segunda implicación es el valor categórico que lo extralingüístico asume en la dicotomía lengua/ sociedad, a razón de que amplía las dimensiones que se analizan en el marco de esta interrelación.

La sociopragmática y el interaccionismo simbólico tienen como aspecto común la interacción verbal. Así, la pragmática social considera que las manifestaciones del lenguaje se producen en escenarios sociales particulares caracterizados por participantes y sus rasgos intrínsecos: el lugar, el evento y la intención -elementos que coinciden con el modelo S-P-E-A-K-I-N-G de Hymes (1972) - . Entre tanto, en el interaccionismo simbólico los espacios sociales se recrean a partir de las acciones frente a frente entre interactuantes que dicen lo que son y aquello que representan. A partir de este nexo entre ambas perspectivas, conviene referirse a la interacción verbal. En línea con lo señalado por Palou y Bosch (2005), la acción verbal se entiende como el encuentro cooperativo y consensuado entre interlocutores, donde se patentan la cosmovisión, el conocimiento del sistema lingüístico, la competencia ideológica y cultural, así como las formas de producción y comprensión del texto. 
Por otro lado, Orechioni (1980) considera que la interacción verbal es "el conjunto de los fenómenos observables cuando [esta] se pone en acción, durante un acto particular de comunicación" (p.39). Este planteamiento diferencia el proceso de enunciar y su resultado. La enunciación incorpora elementos del contexto y deja improntas en el enunciado. En concordancia, Bajtín (1980) lo considera como proceso, en la medida en que se adecúa a las particularidades temáticas, de estilo y estructura. Asimismo, el enunciado se constituye en una unidad del discurso, ya que asume límites que están marcados por el cambio de los roles que asumen los participantes en un evento discursivo. En consecuencia, los enunciados se anclan, se mezclan con los anteriores y con los que le siguen, a causa de la alternación de roles de los sujetos discursivos.

Otra postura sobre la interacción verbal es la que brinda Bajtín (2013), quien la considera como la forma en que el lenguaje se manifiesta en el diario vivir de los sujetos, en la manera como se establecen relaciones comunicativas. La concibe como "la realidad fundamental del lenguaje" que sucede a través del intercambio de enunciados. Además, sigue de manera análoga el desarrollo de la vida social, es decir, la oralidad se transforma mientras el contexto social evoluciona.

En conclusión, la cortesía tiene un recorrido histórico que permite establecer sus bases conceptuales, de manera similar a como sucede con el fenómeno opuesto, la descortesía. La relación verbal es el nexo entre la sociopragmática y el interaccionismo simbólico, pues determina el escenario verbal y social a través de las manifestaciones de uno y otro.

\section{Formas verbales de la descortesía escolar}

De acuerdo con los supuestos teóricos expuestos, los interlocutores en el contexto educativo en eventos cara a cara usan expresiones lingüísticas que se consideran descorteses. Así pues, este apartado analiza las manifestaciones verbales de este tipo que se presentan en las interacciones de los escolares de básica en el contexto educativo. Respecto a estas formas se mencionan el uso de términos peyorativos o disfemismos, así como valoraciones despectivas sobre las características físicas. Se aclara que estas evaluaciones son de uso frecuente en el escenario escolar y dependen de la distancia en las relaciones sociales que existen entre los escolares. Estas se ilustran a través de los siguientes fragmentos:

D: Analiza la situación, Íngrid.

E1: Los papás deberían hablar con Alberto.

E2: Primero hablar con Alberto y después citar a los papás.

$\rightarrow$ Johan: La profe está mamada // ® risas de los compañeros.

D: Está cansada, hijo; tenemos que mejorar nuestro vocabulario. Entonces // continúa el docente // cada uno de nosotros tiene diferentes estrategias para solucionar las cosas.

D: A nosotros nos ocurre eso acá, en el colegio, ¿cierto? ¿A quién le ha pasado?

E: A la mona, que le pegaron un balonazo.

$\rightarrow$ E: Y la mona les echó la madre.

E: Sí, profe: a mí me dio rabia y traté a todos mal.

Otros ejemplos que ilustran cómo los estudiantes de este grado usan formas que afectan la proyección de la persona en la interacción verbal o social son las expresiones de ofensa, como se muestra a continuación: 
- El estudiante se agrede con un compañero por decirle "no sea bobo".

- El estudiante agrede a una compañera por decirle "Elvis" ('el bizco') en la clase de Lengua Castellana; se dialoga con los estudiantes para mejorar el trato en el espacio académico.

- El estudiante de grado sexto se encuentra discutiendo con su compañero; al ser llamados por el docente para saber la situación, uno de ellos interpela al otro diciéndole: “ $i Q u e ́$ va! No sea mentiroso, no le estaba diciendo nada, póngase serio".

- El estudiante dice palabras ofensivas a su compañero y no asume su error.

- Descargo del estudiante: el profesor me dijo "estúpida” delante de mis compañeras.

- E1: "No sea bobo", dirigiéndose a un compañero.

- E2: “Si ve, profe?: si él sigue diciéndome así, no respondo".

Como se expone en este último caso, E1 (hablante 1) pasa por encima de la imagen de su interlocutor al usar una expresión de ofensa ("bobo"), y E2 (hablante 2) detiene esta acción usando una estrategia de amenaza, lo cual se traduce en un indicio de formas de conflicto.

\section{Descortesía y la dimensión extralingüística}

La descortesía no solo se encuentra en formas verbales, pues existen también manifestaciones en los modos de relacionarse que incluyen el manejo del ámbito espacial y las correlaciones que se establecen allí. Algunos gestos reguladores de las inte- racciones verbales, como la mirada y la escucha, toman lugar en las acciones comunicativas, y su ausencia se asume como descortés. De modo que, a continuación, se describe cómo se presentan estos aspectos extralingüísticos en las acciones de los escolares en el escenario educativo.

De entrada, durante las interacciones, se manifiestan algunas maneras de descortesía desde las relaciones de proximidad o lejanía entre los escolares, esto es, desde la proxemia. El manejo del espacio y de las relaciones que se establecen en estos escenarios detalla el tipo de interacción social y verbal que se vive en el contexto escolar. Esto concuerda con la categorización de la proxemia que emerge del trabajo antropológico de Hall (1972), a saber: la distancia personal y sus variaciones (íntima, social y pública). En el escenario escolar se dan muestras de exclusión e inclusión como manifestación de las interrelaciones y las tensiones que se ejercen en pequeños grupos en el aula como formas de descortesía.

Por ejemplo, en relación con los modos de inclusión, se observa que los estudiantes, durante el trabajo de grupos focales, evidencian una reducción gradual de las distancias. A todas luces, la proxemia íntima se acorta por el vínculo de amistad; además, se realizan actos como apoyarse en el compañero para cerrar el espacio aún más. A partir de esta obstrucción que realizan algunos estudiantes en el desarrollo de la actividad, se le da la espalda a otro de ellos, lo que le impide formar parte de la tarea escolar. Ciertamente, esto constituye una de las formas de exclusión, y se ilustra en esta descripción: "Los estudiantes le abren espacio al compañero de momento, pero mientras el profesor está con los otros grupos, E1 coloca el brazo sobre el hombro de E2 y le dan la espalda a E3, que forma parte de su colectivo de trabajo".

Cuando la relación está marcada por la diferencia, y quienes están en el uso de la palabra 
muestran poco interés por escuchar o un escaso gusto en relación con los deseos del otro, se constituye una forma descortés en las relaciones escolares del día a día. El aspecto de desinterés por un enunciado desconoce la heteroselección y la autoselección (Calsamiglia y Tusón 1999) y sin lugar a dudas se llega a un punto en el que se presenta la ausencia o aseleccción (-selección), esto es, el hablante se priva de escoger quien debería continuar con lo dicho. No obstante, este bache en la comunicación se considera descortés, ya que pasa por encima de lo que pretende enunciar alguno de los partícipes del acto comunicativo.

Como hemos dicho antes, el desconocimiento de la comprensión auditiva, y en especial de la competencia pragmática al descartar un enunciado de algún compañero, valida la descortesía. Esto se debe a que se presenta un rechazo de la intención comunicativa al disentir con los propósitos discursivos y de la cosmovisión que pone de manifiesto el escolar con sus compañeros.

Cabe aclarar que la comprensión auditiva se conjuga con la forma en la que los eventos comunicativos orales se enuncian, pues como contempla Lugarini (1995) en ella se establece una relación entre los elementos verbales y los no verbales. Es decir, el hablante enuncia algo, el oyente centra su atención con su mirada y se establece un nexo entre lo verbal y lo extraverbal. Dicho de otra manera, se establece un diálogo entre lo verbal y lo gestual que permite que el flujo comunicativo siga la corriente. Esto se describe a continuación:

P4: Escuchar es poner atención a lo que dice y hace alguien, y oír es una actividad sin esfuerzo.

P5: Escuchar es poner atención o estar dispuesto para comprender al otro, y oír no necesita esfuerzo.
P6: Escuchar es mirar y comprender a la persona con la que converso, y oír es sólo sentir las vibraciones.

Como se muestra, existen elementos extralingüísticos que están presentes en la comunicación, pero su ausencia en la actividad escolar y en las relaciones del cotidiano se perciben como descorteses.

\section{La cortesía verbal como elemento de alteridad}

La cortesía como manifestación sociopragmática se debe entender desde las relaciones verbales y sociales que se establecen entre un yo presente que no se desliga de la presencia del otro. Así las cosas, la comunicación pierde el carácter centrado en las necesidades personales; se transforma en escenario donde coexisten múltiples voces y se gestionan acuerdos tácitos.

En consecuencia, en este acápite se analizan algunos modos verbales de cortesía y uno de ellos es el uso discursivo del plural de modestia ("nosotros"), empleado para recibir mayor estimación por parte de quien lo escucha, así como de los partícipes de la interacción verbal. Muestra de esto es el siguiente fragmento del corpus: "Nosotros pensamos que el niño que no está pensando igual actúa así porque es diferente ||, mientras que el otro niño que hace bullying busca ser aceptado". Claramente, se le da mayor valor a la imagen de todo el grupo que a la imagen propia; dicho de otra manera, se establece una relación desequilibrada entre la imagen propia, que no cobra importancia, mientras que la enunciación discursiva se realiza desde la forma del plural para incluir a los presentes en el acto comunicativo. Así, se minimiza el sentimiento de rechazo al decir "yo pienso", para ahora resaltar la simpatía del colectivo al expresar "pensamos". 
Otro de los modos en que la cortesía se evidencia en el contexto escolar es en las formas de sugerir o felicitar en actividades en grupos, como se deriva de este mensaje: "Con un poco más de trabajo, la obra quedaría mejor, pero lo hicieron bien [...]; también felicitar a Luis, porque no se sabía el papel y se lo aprendió". Frente a estos enunciados se concuerda con lo que Searle (2015) expresa: "El dispositivo indicador de la función muestra cómo debe ser tomada la proposición, o, dicho de otra manera, qué fuerza ilocucionaria ha de tener, esto es, qué acto ilocucionario está realizando el hablante al emitir la oración" (p. 14). Igualmente, la felicitación y la sugerencia cumplen con las reglas de sinceridad de los actos de habla, por cuanto quien enuncia la proposición asume la autenticidad de lo dicho e intenta convencer de que ello es veraz, y su efecto será, entonces, la distensión en las relaciones escolares.

Existen diferentes estrategias que mitigan los errores de la comunicación. De esta suerte, la asertividad y la cortesía estratégica en el contexto escolar como espacio de aprendizaje y socialización diario reducen el peso de las faltas comunicativas. Esto gracias a que ambas transitan entre lo agresivo y lo pasivo, razón por la cual la interacción comunicativa oral es efectiva.

En consecuencia, se establece una relación entre la asertividad y la cortesía estratégica. Según Escandel (como se citó en Trujillo y García 2004) la cortesía estratégica se considera como "el conjunto de "maniobras lingüísticas" de las que puede valerse el hablante para reducir al mínimo el conflicto con su interlocutor cuando los intereses de ambos no son coincidentes" (p.123), y la asertividad reduce las posibles maneras de agresión o pasividad de los participantes del evento comunicativo. Entonces, ambas persiguen la misma intención que no es otra cosa que fortalecer el contexto interaccional a través de las buenas interrelaciones en las que se conserva, a su vez, una imagen positiva.
Como se muestra, la cortesía verbal pone en un mismo escenario a los interactores del acto comunicativo. En esta escena transitoria tanto el yo presente como el otro omiten errores en la comunicación al asumir una actitud de empatía entre ellos, al usar expresiones que hacen que la interacción verbal fluya en pro de ambos, sin atacar la imagen que se proyecta en ella.

\section{La cortesía desde lo no verbal}

Por otro lado, desde lo extralingüístico, la mirada se convierte en regulador de la interacción. Si bien no se considera como una manera de cortesía, sí constituye una forma próxima a ella, debido a que el contacto visual centra la atención en lo que se dice y refuerza los lazos para la construcción comunicativa. Esto lo confirma la afirmación de Poyatos (1994): "Podemos comunicar palabras con un mínimo casi imperceptible de paralenguaje o kinésica, con un gesto y sin emitir ningún sonido, $\mathrm{o}$ con un solo carraspeo y una expresión facial" (p.144). Adicionalmente, se convierte en un marcador del interés por continuar en eventos conversacionales, o bien, descartar la participación en ellos; pero además de ser un elemento que permite la participación, la mirada determina la organización y el orden de los turnos conversacionales, donde prevalece la heteroselección al escoger quién continúa con lo que se enuncia en el evento comunicativo.

La mirada como regulador de la interacción verbal tiene un valor agregado, ya que alienta a tomar parte en las conversaciones o de las actividades escolares. De modo que cuando un estudiante o el maestro mismo desea que otro miembro de la comunidad escolar continúe con el hilo conversacional, no se hace necesario que lo enuncie, pues a través de ella se logra. También es un indicador de que la persona debe continuar o acelerar en la progresión discursiva mientras se 
desarrolla una actividad en el aula. En síntesis, además de ayudar en la gestión de la interacción comunicativa, ésta valora la imagen que se proyecta en el escenario comunicativo.

\section{Sobre la modalización}

Desde otra arista, el empleo de la modalización se convierte en una forma de cortesía en el aula, porque permite el flujo de interacción verbal sin afectar la imagen de los interlocutores, lo que constituye la imagen bifocal. Este fenómeno, en palabras de Haverkate (1996), corresponde a "la mitigación de fuerza asertiva que se realiza particularmente mediante el empleo de predicados doxásticos" (p.3). Se entiende por estado doxástico aquel que indica que el hablante no está seguro de que el contenido de su creencia corresponda a los eventos que suceden en la realidad; el autor confirma que el uso de este tipo de predicados se convierte en una estrategia de cortesía bifocal, de modo que protege la imagen propia y la del interlocutor. Este hecho se evidencia en este fragmento del corpus:

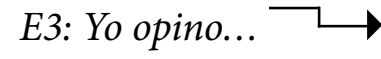

\section{D: Sí, hijo, ¿qué opinas?}

E3: Yo opinaría que es la número catorce [Lee el texto correspondiente a ese numeral].

\section{E4: Yo creería... $\longrightarrow$}

\section{D: Cuéntenos.}

E4: Yo creería que debería ser la número dos. [...] Entonces esa debería estar mucho más abajo, considero, ¿no?

Por otro lado, como anuncia Briz (2005), la atenuación se asume como una expresión lingüística que deriva de la cortesía. Así, como se mostró anteriormente, el uso de verbos performativos como opinar, pensar o creer en el modo condicional se convierten en herramientas del sistema lingüístico que cumplen con una función de cortesía o atenuadora. Vale la pena resaltar que la aceptación de un atenuante depende de la evaluación del oyente sobre lo que un hablante emite (mensaje); en otras palabras, gracias a la valoración de estos últimos elementos se mitiga la fuerza de lo dicho. La modalización es una estrategia conversacional contextual; de esto se deriva que en los eventos cara a cara ella sea el resultado de una producción de libre albedrío del hablante y el oyente, quienes, de igual manera, tienen en su poder ponderarla como mitigadora o no.

\section{CONCLUSIONES}

La (des)cortesía se convierte en un elemento moderador de la actividad social y verbal. Esta estratagema, una vez enunciada por un hablante $(\mathrm{H})$, indica que la imagen que este proyecta está por encima del oyente $(\mathrm{O})$. Además, muestra el poco interés que $\mathrm{H}$ tiene por aquello que formula $\mathrm{O}$, y en consecuencia, desaprueba su rol en la interacción verbal, causa fallas en el proceso comunicativo y genera conflictos en su desarrollo. La cortesía, en cambio, provoca distensión en las relaciones que se establecen entre los participantes del evento comunicativo. La deferencia por la noción personal cumple con el objetivo de respeto en el contrato comunicativo entre las partes. De este modo, la relación comunicativa fluye a plenitud en ambas partes, o sea, la intención comunicativa del hablante es asimilada por el oyente, sin que se genere ningún tipo de malestar.

Se manifiesta que la cortesía refleja la manera en que todo interactor quiere ser tratado. De manera que su uso se convierte en una forma 
de empatía que mitiga los errores en la comunicación y fortalece el proceso comunicativo, a diferencia de la descortesía que crea conflictos en la acción comunicativa y hace que las personas eviten el contacto con las personas que dispongan de esta estrategia.

Tanto la cortesía como su contraparte desempeñan un rol en la construcción de imagen de los escolares. Por un lado, la cortesía permite que los estudiantes, en el escenario académico, continúen en la construcción de su imagen al enunciar algo y ser aprobados. En cambio, la descortesía produce más rechazo, por ser visible en el contexto escolar, y en ciertos momentos produce atisbos de formas de conflicto interpersonal y de autoridad, en especial cuando las manifestaciones descorteses provienen del docente.

La modalización se genera en eventos cara a cara, cuya visibilización deriva del contexto en que sucede. En el caso particular de esta investigación, la conversación se convirtió en eje central. Por ello, es necesario aclarar que esta es una forma de interacción social y verbal que se vale de elementos lingüísticos y códigos no verbales que permiten su gestión. Si se refiere a los códigos lingüísticos, entonces se observará que la atenuación se usa como estrategia para permitir el flujo de la plática, que mitiga la intención de aquellos enunciados que se producen entre los sujetos que intervienen en los eventos comunicativos orales.

En el proceso de investigación cobró relevancia el aspecto extralingüístico. Esto pues brindó luces sobre lo que se considera descortés. Esto se ve desde la proxemia y los elementos reguladores de la interacción verbal como la escucha y la mirada al descartar el acceso de una persona a un grupo. Lo anterior concuerda con los postulados de la pragmática social al considerar que uno de sus deberes es convertir la dimensión extralingüística en una categoría que emerge del cuadro bifronte lenguaje y sociedad.

Por último, se observa que el macro campo de la oralidad es multisistémico. En este espacio se encuentran diferentes manifestaciones de su existir: lo verbal y lo no verbal. De manera similar sucede con la interacción verbal, la cortesía y la resolución del conflicto, porque se van hilando a través de algunas expresiones o gestos. Cabe aclarar que en la interacción verbal se puede manifestar la (des)cortesía en ambas formas, pero es el $\mathrm{O}$ quien evalúa como asume los enunciados o los actos comunicativos.

\section{REFERENCIAS BIBLIOGRÁFICAS}

Arias, F. (2006). El proyecto de investigación. Introducción a la metodología científica. (5 $5^{\mathrm{a}}$ ed.). Caracas-Venezuela: Editorial Espíteme.

Bajtín, M. (1980). El problema de los géneros discursivos. En Estética de la creación verbal. Ciudad de México: Siglo XXI.

Bajtín, M. (2013). El principio dialógico. Bogotá: Instituto Caro y Cuervo.

Bolívar, A. (2005). La descortesía en la dinámica social y política. Actas del lI Coloquio Internacional EDICE "Actos de habla y cortesía en distintas variedades del español: perspectivas teoricas y metodológicas" Costa Rica: Universidad de Costa Rica.

Bravo, D. (2005). Categorías, tipologías y aplicaciones. Hacia una redefinición de la "cortesía comunicativa”. En D. Bravo. (Ed.), Estudios de la (des) cortesía en español. Categorías conceptuales y aplicaciones a corpora orales y escritos (pp. 21-52). Buenos Aires: Dunken.

Briz, A. (2005). Eficacia, imagen social e imagen de cortesía. Naturaleza de la estrategia atenuadora en la conversación cotidiana española. En D. Bravo. (Ed.), Estudios de la (des) cortesía en español. Categorías conceptuales y aplicaciones a corpora orales y escritos (pp. 53-91). Buenos Aires: Dunken. 
Brown, P. y Levinson, S. (1987). Politeness: Some universals in language usage. Cambridge: Cambridge University Press.

Calsamiglia, H. y Tusón, A. (1999). Las cosas del decir. Manual del análisis del discurso. Recuperado de https://universitas82.files.wordpress. com/2013/08/las-cosas-del-decir.pdf

Devis, E. (2011). La entonación de (des)cortesía en el español coloquial. Recuperado de www. publicacions.ub.edu/revistes/phonica7/ documentos/733.pdf

Goffman, I. (1991). Los momentos y sus hombres. Barcelona: Paidós.

Gurdián A. (2007). El paradigma cualitativo en la investigación socio-educativa. Costa Rica: UCR.

Gumperz, J. (1981). Lenguaje y sociedad. Barcelona: Anagrama.

Hall, E. (1972). La dimensión oculta. Buenos Aires: Siglo XXI.

Haverkate, H. (1987). El análisis de la cortesía comunicativa: categorización pragmalingüística de la cultura española. En D. Bravo y A. Briz (Coords.), Pragmática sociocultural: estudios sobre el discuros de cortesía en español (pp. 55-66). Barcelona: Ariel.
Haverkate, H. (1996). Estrategias de cortesia. Analisis intercultural. Recuperado de cvc.cervantes.es/ ensenanza/biblioteca_ele/asele/pdf/07/07_0043. pdf

Hymes, D. (1972). On comunicative compentence. Recuperado de wwwhomes.uni-bielefeld.de/ sgramley/Hymes-2.pdf

Lugarini, E. (1995). Hablar y Escuchar. Por una didáctica del "saber hablar" y del "saber escuchar". Recuperado de www.quadernsdigitals.net/datos/ hemeroteca/r_3/nr_42/a_638/638.html

Orechioni, K. (1980). La enunciación: de la subjetividad en el lenguaje. Buenos Aires: Edicial.

Palou, J. y Bosch, C. (2005). La lengua oral en la escuela: diez experiencias didácticas. Barcelona: Graó.

Poyatos, F. (1994). La comunicación no verbal: cultura, lenguaje y conversación. Madrid: Istmo.

Searle, J. (2015). ¿Qué es un acto de habla? Recuperado de http://www.upv.es/sma/teoria/ sma/speech/Que\%20es\%20un\%20acto\%20 de\%20habla.pdf

Trujillo, J. R. y García J. (2004). Negociación, comunicación y cortesía verbal: Teorías y técnicas. México: Limusa. 